\title{
CONSCIENTIZAÇÃO AMBIENTAL CONTRIBUINDO PARA ELIMINAR O DESPERDÍCIO E AMPLIAR AS AÇÕES A FAVOR DO MEIO AMBIENTE
}

Environmental awareness contributing to eliminating waste and expanding actions in favor of the environment

Conciencia ambiental que ayuda a eliminar los residuos y ampliar las acciones a favor del medio ambiente

\section{Viviane Grams Carvalho *1, Antônio Carlos Estender ${ }^{2}$}

${ }^{1}$ Curso de Administração, Universidade Guarulhos, São Paulo, Brasil.

${ }^{2}$ Coordenador dos Cursos de Administração, Logística e Recursos Humanos, Unidade Bonsucesso, Universidade Guarulhos, São Paulo, Brasil.

*Correspondência: Universidade Guarulhos, Administração.Praça Tereza Cristina 88, CentroCEP:07023070 - Guarulhos,SP-Brasile-mail: viviane_grams@yahoo.com.br

\section{RESUMO}

Este trabalho se propõe a compreender as percepções dos stakeholders sobre como a conscientização ambiental pode contribuir para eliminar o desperdício e ampliar as ações a favor do meio ambiente e para a aplicação prática, visa também solucionar problemas específicos, no caso, do desperdício e o descarte incorreto. Tem como objetivo verificar na visão e vivência dos stakeholders; no ramo da saúde pública, os fatores importantes para o desenvolvimento de um sistema de gestão sustentável, para agregar valor à organização. O trabalho foi realizado por meio de estudo de caso, entrevistas de natureza qualitativa e exploratória, sendo a coleta de dados realizada através de um questionário destinado a 25 stakeholders. Observou-se que os principais resultados foram o desconhecimento do assunto por parte dos servidores e usuários e a falta de incentivo. Diante do exposto, é recomendado estabelecer normas para que as entidades governamentais implantem um sistema de gestão sustentável para otimizar os recursos utilizados e ampliar a conscientização, para isso as organizações devem incentivar a conscientização ambiental da população e manter o meio ambiente saudável.

Palavras-chave: Educação Ambiental; Desperdício; Sustentabilidade.

\section{ABSTRACT}

This work aims to understand the perceptions of stakeholders on how environmental awareness can contribute to eliminate waste and extend the actions in favour of the environment and to the practical application, it also aims to solve specific problems, in the case of waste and incorrect disposal. Aims to check the vision and experience of stakeholders; in the field of public health, the important factors for the development of a sustainable management system, to add value to the organization. The work was conducted through case study, qualitative and exploratory interviews, being data collection accomplished via a questionnaire for the 25 stakeholders. It was observed that the main results were the ignorance of the subject by the servers and users and the lack of incentive. On the above, it is recommended to establish standards for governmental entities to deploy a system of sustainable management to optimize resources and increase awareness, for it organizations should encourage the environmental awareness of the population and keep the environment healthy.

Keywords: Environmental education; Waste; Sustainability. 


\section{RESUMEN}

Este trabajo tiene como objetivo entender las percepciones de actores sobre conciencia ambiental cómo pueden contribuir a eliminar el desperdicio y extender las acciones a favor del medio ambiente y a la aplicación práctica, también tiene como objetivo resolver problemas específicos, en el caso de disposición de basura y el incorrecto. Tiene como objetivo comprobar la visión y experiencia de los actores; en el campo de la salud pública, los factores importantes para el desarrollo de un sistema de gestión sostenible, para agregar valor a la organización. El trabajo se llevó a cabo a través del estudio de caso, entrevistas cualitativas y exploratorias, siendo la recopilación de datos logrado a través de un cuestionario para los 25 actores. Se observó que los principales resultados fueron el desconocimiento del tema por los servidores y los usuarios y la falta de incentivo. En lo anterior, se recomienda establecer normas para las entidades gubernamentales implementar un sistema de gestión sostenible para optimizar recursos y aumentar el conocimiento, las organizaciones deben fomentar la conciencia ambiental de la población y mantener el ambiente sano.

Descriptores: Educación ambiental; residuos; Sostenibilidad.

\section{INTRODUÇÃO}

Donaire (2012) e o Ministério do Meio Ambiente (2016) vêm analisando o objeto de pesquisa, conforme apontado na revisão de literatura, em seus diferentes níveis de entendimento e aplicação ao contexto organizacional. Pode-se encontrar na literatura definições para gestão ambiental; sustentabilidade, conscientização ambiental, desperdício, o que demanda a construção de um modelo teórico/empírico/gerencial que explicite como estes diferentes conceitos se articulam e podem contribuir para o entendimento de propostas para o desenvolvimento organizacional.

A questão ambiental foi inserida nas organizações desde a conferência das Nações Unidas sobre meio ambiente em Estocolmo na Suécia em 1972, houve uma maior evolução com a Conferência de 1992, conhecida como ECO-92 que ocorreu no Estado do Rio de Janeiro, em 1993 foi criada a ISO 14001, em 1997 teve a criação do Conselho Empresarial Brasileiro de Desenvolvimento Sustentável e a assinatura do Protocolo de Kyoto, em 2002 ocorreu a Rio+10 ou Conferência das Nações Unidas sobre Ambiente e Desenvolvimento Sustentável, em Johannesburgo, África do Sul, onde revisaram as metas da agenda 21 .
$\mathrm{Na}$ literatura acadêmica sobre conscientização ambiental, desperdícios, relacionados com o setor na Saúde Pública, existem poucos estudos sobre o objeto de pesquisa (BURGESS; SIMONS, 2005). Os trabalhos identificados na literatura foram Donaire (2012), Campos; Lerípio (2009) os mais significativos na literatura.

Este trabalho visa analisar: como a conscientização ambiental pode ocasionar a diminuição do desperdício de materiais na saúde pública? Por que a conscientização ambiental não é praticada para evitar o desperdício de materiais? Quais os impactos que a conscientização e o desperdício trazem para a sociedade? Um conjunto de ações pode ser estabelecido pela organização, para que possa agregar mais conhecimento e promover a mudança no ambiente organizacional, pois o desperdício de material é evidente em todas as áreas do serviço público, o que ocasiona aumento dos custos e despesas, a falta de conhecimento dos servidores, quanto ao descarte correto de recursos também impacta de forma negativa o meio ambiente.

O estudo visa ampliar a visão dos servidores quanto à importância da sustentabilidade, formando equipes especializadas, que poderão verificar e 
fiscalizar as ações no ambiente de trabalho, além de promover parcerias com empresas, buscando diminuir os gastos nas compras de materiais e estimular a reciclagem; através da disseminação do conhecimento com campanhas e palestras; utilizar a tecnologia como meio para incentivar e apresentar aos usuários a importância do assunto; montar um núcleo específico para elaboração do planejamento necessário.

Os objetivos desta pesquisa são: compreender como a conscientização ambiental ocasiona a diminuição do desperdício na saúde pública; analisar porque a conscientização ambiental não é praticada para evitar o desperdício; verificar quais os impactos que a conscientização e o excesso de desperdício trazem para a sociedade; contribuir com o desenvolvimento da sustentabilidade no ambiente organizacional; identificando meios de reduzir os gastos, ampliando a conscientização dos servidores, apresentando a importância da educação ambiental para o desenvolvimento de um meio ambiente saudável; realizar levantamento das percepções dos stakeholders sobre a conscientização ambiental e o desperdício na saúde pública; elaborar ações baseadas nas percepções das situações vivenciadas pelos Stakeholders para produção de ações que possibilitem atingir os objetivos.

Segundo Martins (2008) o ambiente de trabalho é um fator importante, devido aos estímulos que os trabalhadores recebem, pois ficam expostos as atitudes e problemas dentro da organização, por conseguinte o estudo está focado na melhoria do ambiente de trabalho e a ampliação da visão dos servidores diante dos benefícios que a conscientização ambiental pode trazer para o meio ambiente, diminuindo o desperdício, visando o crescimento da sustentabilidade e a redução de custos quanto aos materiais utilizados na elaboração de trabalhos administrativos e diminuir o impacto no meio ambiente utilizando a Administração Pública como exemplo para a população.

O presente estudo visa contribuir para a elucidação de questões relacionadas ao objeto de pesquisa. Almeja-se preencher a lacuna empírica identificada na relação entre Donaire (2012), Ministério do Meio Ambiente (2016) e Campos; Lerípio (2009). A contribuição mais relevante é de natureza empírica, pois durante a realização da pesquisa, constatou-se a necessidade de estudos relacionados ao objeto de pesquisa, para assim gerenciar as metas e objetivos definidos pela organização, desta forma é possível contribuir para a melhora do ambiente organizacional.

A sustentabilidade é um tema que deve ser tratado minuciosamente para melhorar o desempenho do atual cenário do país, devido à importância que as organizações têm para a sociedade, estas devem investir na elaboração de um sistema de gestão sustentável que possa transformar a vida dos seus colaboradores, para que estes possam assumir e aderir aos costumes, facilitando a transmissão da informação para todos. A empresa deve planejar as ações, para incentivar a propagação do conhecimento necessário, através do seu principal capital, as pessoas. A organização deve pensar no bem-estar dos seus colaboradores e da sociedade, incentivando e estruturando meios para desenvolver melhores práticas de sustentabilidade.

Para o desenvolvimento da pesquisa, em termos metodológicos, será adotada a abordagem qualitativa. Segundo Collis; Hussey (2005). Em relação aos procedimentos serão realizadas entrevistas. As pesquisas deste tipo se caracterizam pela interrogação direta das pessoas cuja percepção se deseja conhecer. Basicamente, procede-se à solicitação de informações via questionários a um grupo de stakeholders acerca do problema estudado para em seguida, mediante análise, obter as 
conclusões correspondentes aos dados coletados. A população entrevistada foi de 25 pessoas de diferentes hierarquias e as amostras foram analisadas de forma empírica.

O estudo está estruturado em cinco seções, além desta introdução. Na primeira seção é discutida a questão da revisão de literatura; a seguir são detalhados os aspectos metodológicos; estudo de caso, pesquisa bibliográfica, pesquisa exploratória, entrevistas, entre outros; na terceira seção, os resultados; na quarta seção discussões e na última seção, são expostas as considerações finais.

\section{MATERIAIS E MÉTODOS}

\section{Disseminação do conhecimento através de campanhas e palestras}

De acordo com Lima (2004), a escola é um espaço privilegiado onde podemos impulsionar a postura e a responsabilidade referente ao meio ambiente, pois podemos incentivar e atingir a sociedade por meio das famílias, gerando a educação e a conscientização ambiental, trazendo conhecimento e estimulando a prática de boas ações para a preservação do meio ambiente. Sendo assim, deve-se identificar meios de alcançar a conscientização através da educação, elaborando estratégias para manter a sociedade informada quanto à importância da preservação do meio ambiente.

Segundo Cortez; Ortigoza (2007), no mundo ocorre um debate em torno da diminuição da quantidade de lixo produzido, sendo assim, observamos que alguns países estão preocupados com o meio ambiente, tentando achar soluções como a reciclagem e diminuição da produção de lixo que uma sociedade produz, buscando minimizar os resíduos e melhora qualidade de vida. Assim pode-se observar a necessidade, da educação ambiental ser transmitida à sociedade. No município de Caxias do Sul, a empresa Codeca mantém vários projetos voltados para uma gestão de qualidade, planejamento adequado para retratar os valores necessários e manter a conscientização dos munícipes.

De acordo com Quintas (2006) a educação ambiental constrói valores sociais, conhecimentos, habilidades, atitudes e competências voltadas para a conservação do meio ambiente, sendo assim, a organização pode ampliar e incentivar a conscientização através da educação ambiental dos servidores. Assim, os colaboradores podem desenvolver as mudanças desejadas pela empresa, transformando o clima organizacional, oferecendo ideias e ações que possam favorecer a ampliação do conhecimento e alcançar o objetivo de conscientizar todos os servidores e usuários.

Segundo Barbieri (2007), existem dois fatores que influenciam as atitudes ambientais: o governo e a sociedade, pois o governo como um órgão responsável por difundir o conhecimento e incentivar novas atitudes, deve desenvolver práticas voltadas para a preservação do meio ambiente; entretanto, a maioria de seus órgãos não apresentam projetos voltados para a conscientização e ampliação do conhecimento dos servidores e usuários, impedindo assim, a disseminação de novos conceitos e aprendizagem por parte da sociedade, por este motivo as organizações devem contribuir com a educação ambiental em um processo contínuo para otimização da conscientização ambiental.

Segundo Souza, et al (2014) às pesquisas de aprendizagem devem ter foco específico e contínuo; sendo assim, o foco das campanhas realizadas para estimular práticas de disseminação do conhecimento nas empresas, devem ser bem planejadas e estruturadas, para que as informações sejam repassadas corretamente, atingindo assim, de forma 
positiva o público alvo da pesquisa; a fim de estimular as mudanças, expondo os benefícios que a conscientização ambiental traz para a empresa e para a sociedade, indicando como os recursos podem ser utilizados, descartados e reciclados corretamente sem prejudicar o meio ambiente.

De acordo com Gonçalves; Mourão (2011), a área de treinamento deve ser considerada estratégica para a empresa, sendo assim, devem-se treinar os colaboradores para adquirir conhecimento e consequentemente ter um bom desempenho, a fim de compartilhar das novas experiências e formar novas opiniões a respeito do meio ambiente; a organização deve determinar o objetivo a ser atingido de forma clara, para agregar mais valor no ambiente de trabalho, gerando novas atitudes, que auxiliem na evolução da responsabilidade sócio ambiental. Para que a conscientização seja praticada no ambiente organizacional é necessário que a empresa estimule constantemente seus colaboradores.

De acordo com Donaire (1994), a conscientização da organização ocorre em três fases: controle ambiental nas saídas, integração do controle ambiental nas práticas e processos industriais; bem como, é utilizado em outras organizações como na Universidade Federal de Ciência da Saúde de Porto Alegre onde é relacionado à busca pela promoção de ações para atingir a meta estabelecida, promovendo a inserção da comunidade em projetos de proteção ao meio ambiente, e assim, poder ampliar o conhecimento, com o intuito de motivar a mudança nas ações junto com a sociedade, para preservar o meio ambiente.

$$
\text { De acordo com Ashley (2002) as }
$$
organizações devem assumir uma responsabilidade e um compromisso com a sociedade, desempenhando atitudes que afetem positivamente a comunidade, através desta ideia, a organização deve procurar disseminar o conhecimento e expandir positivamente a responsabilidade ambiental. As entidades públicas podem aproveitar sua visibilidade, para atingir a sociedade, de forma que possa favorecer a disseminação do conhecimento, por conseguinte, atender a expectativa de aumentar o consumo sustentável e a qualidade de vida dos stakeholders, visando o crescimento da conscientização ambiental na população.

\section{A tecnologia como instrumento de conscientização ambiental}

De acordo com Dallas (2009), a redução de consumo deve ser estudada para que a educação e a conscientização ambiental obtenham um avanço na sociedade; por conseguinte, utilizar a tecnologia como meio para desenvolver e conscientizar a sociedade, para que, busquem a diminuição do desperdício, através da reciclagem, coleta seletiva, atitudes sustentáveis, bem como, buscar novos meios que possam ser úteis para expandir e apresentar a importância da conscientização ambiental aos usuários e servidores, mostrando um caminho mais sustentável, através de ações responsáveis no ambiente de trabalho e no dia a dia de cada um.

De acordo com Layrargues (2000), a utilização da tecnologia limpa é a solução ambiental, sustentada pela ISO 14000 e o Sistema de Gerenciamento Ambiental, onde podemos localizar os meios de utilizar a tecnologia a favor do meio ambiente, trazendo para a realidade as formas de ampliar a conscientização e identificar meios de incentivar os stakeholders, a reduzir o desperdício causado pela má gestão dos recursos e contribuir para o desenvolvimento da conscientização e educação ambiental na organização.

Para Soares, et al (2008), dentre várias medidas para conservação do meio ambiente, existe o programa de gerenciamento de riscos; que pode 
melhorar o desempenho das ações entre os departamentos da empresa, através deste programa, pode-se gerenciar a conscientização, a integração, o apoio da direção, documentação e controle das ações, com intuito de verificar o progresso da conscientização dos stakeholders. Assim, poder controlar e identificar as principais falhas da gestão para reduzir os gastos, através do controle.

Young; Lustosa (2001), apresenta outra solução para poluição, a PP (pollution prevention) através de uma gestão inovadora, utilizando tecnologia limpa, para criar eficiência produtiva gerando a redução de resíduos e a reciclagem de produtos; entretanto não podemos deixar de levar em consideração o déficit de conhecimento dos stakeholders, sendo assim, deve-se utilizar esta gestão, para identificar meios de reduzir os gastos e aumentar o conhecimento e a conscientização dos servidores quanto à importância da reciclagem e desenvolver dentro do ambiente organizacional uma cultura sustentável.

Rosenberg (1976), afirmou que podemos colocar em prática a tecnologia para reduzir e proporcionar novo uso aos resíduos; pois temos, capacidade de elevar as ações corretivas a favor do meio ambiente; sendo assim podemos elaborar projetos utilizando a tecnologia para verificar e identificar, quais os impactos que a conscientização pode trazer para a organização e ajustar as ações necessárias para disseminar o conhecimento, após a constatação dos itens necessários, à empresa deverá colocar em práticas estas ações para facilitar a redução dos gastos.

\section{Segundo Herrera (1982), a tecnologia} proporcionou à humanidade a facilidade de poder compreender um risco e uma possibilidade, assim, manifestando a melhoria do meio ambiente, tornando-o melhor com desempenho em qualidade ambiental; o Estado do Rio de Janeiro adotou um modelo de Gestão de Qualidade focada no desenvolvimento e na melhoria contínua, além destas, o Estado deseja gerenciar um sistema de informações, processos, recursos humanos e também a otimização dos custos, que poderá ampliar a excelência em seus projetos, isto nos mostra que a criação de um sistema que gerencie as despesas e o custos pode melhorar o desempenho e aumentar a satisfação na elaboração dos trabalhos.

\section{Montar um núcleo específico para elaboração do planejamento}

Segundo Martins (2008), o clima organizacional é um conceito importante, os estudos apontam que os trabalhadores estão expostos a qualquer comportamento, ou seja, atitudes no ambiente de trabalho, interferem no desenvolvimento dos colaboradores; diante disso, destacamos que a cultura organizacional deve estabelecer métodos e ações que convergem com a sustentabilidade, com intuito de conscientizar de forma ágil e eficiente, por conseguinte, modelar as atitudes dos funcionários e usuários, para assegurar a elaboração dos planejamentos estabelecidos da organização.

Segundo Barata; et al (2006), a gestão ambiental deve interagir com todos os setores e departamentos da empresa para unir a força de trabalho, como também, transmitir todas as informações que são apresentadas para gerar o conhecimento e assim conseguir mapear os processos, para reduzir os riscos e estabelecer o melhor método a ser seguido, para alcançar o objetivo da empresa. Sendo assim a empresa poderá analisar o conjunto de ações que irá agregar mais conhecimento e trazer a mudança organizacional.

Segundo Campos; Liripio (2009), a organização pode utilizar como forma de análise e avaliação, a auditoria ambiental, de forma que, 
consiga manter o desenvolvimento do sistema e fiscalizar, e para isso é necessário manter a ordem de todos os fatores importantes, fazer um acompanhamento para identificar os meios que mais auxiliam na diminuição do desperdício, na análise do desenvolvimento do projeto, de modo que, a empresa possa monitorar o andamento da conscientização, da sustentabilidade e identificar os benefícios que a conscientização ambiental traz para a empresa.

A ISO 14001, estabelece diretrizes básicas para o desenvolvimento de um sistema de gestão ambiental; para que as organizações coloquem em prática políticas e metas ambientais sustentáveis, de forma que as mesmas possam desenvolver e estruturar a gestão ambiental, visando à diminuição do desperdício se baseando na redução, reciclagem e na reutilização. Por conseguinte, apresentar a importância do meio ambiente, ampliando a conscientização, apresentando os benefícios que tais ações podem trazer para diminuir o impacto ao meio ambiente. Essas ações podem impactar o desempenho das pessoas no ambiente de trabalho e nas suas residências, trazendo a mudança e a conscientização ambiental.

O ministério do meio ambiente, dispõe de um programa chamado A3P - Agenda Ambiental na Administração Pública, que visa, ampliar a conscientização dos servidores através da criação de um grupo responsável, de forma que as organizações desenvolvam uma gestão com ações que visa: eliminar os desperdícios, melhorar o desempenho e estimular a qualidade no ambiente de trabalho, através de uma nova cultura institucional. Portanto, a organização necessita de pessoas habilitadas e comprometidas para transmitir as informações necessárias aos usuários e servidores, gerando a conscientização no ambiente organizacional. Este núcleo irá desempenhar as atividades necessárias para ampliar a visão dos servidores quanto à importância da sustentabilidade, proporcionando assim a melhoria no ambiente de trabalho.

Segundo Silva; Barki (2012), os gestores públicos, servidores e tomadores de decisões precisam entender que o Estado deve fornecer instrumentos baseados na sustentabilidade; sendo assim, é necessário que seja feita a publicação de editais sustentáveis, para priorizar a conscientização e a credibilidade com a sociedade, mostrando a importância do Selo Socioambiental obedecendo aos critérios estabelecidos pelo próprio Estado, a organização deve agregar mais licitações com produtos que seguem os critérios da sustentabilidade, para colocar em prática novas ações, mantendo o controle dos gastos públicos, e também procurar parcerias com empresas que buscam o mesmo objetivo.

O Plano de Ação para a Produção e Consumo Sustentáveis - PPCS, é uma ação do MMA que tem o objetivo de fomentar políticas, programas e ações que promovam a produção e o consumo sustentáveis no país. Enfoca em seis áreas principais: Educação para o Consumo Sustentável; Varejo e Consumo Sustentável; Aumento da reciclagem; Compras Públicas Sustentáveis; Construções Sustentáveis e Agenda Ambiental na Administração Pública (A3P). Esse último programa incentiva a incorporação de atitudes sustentáveis na rotina dos órgãos públicos do país. Para que as políticas públicas sejam cada vez mais próximas aos cidadãos, o MMA coordena as conferências do meio ambiente, cuja proposta é ouvir governo nacional e local, iniciativa privada, organizações não governamentais e cada brasileiro sobre a gestão ambiental no país. (Ministério do Meio Ambiente/2011).

O ministério do meio ambiente, disponibiliza projetos para que qualquer servidor interessado possa, realizar ações diferentes no âmbito do seu departamento, e libera o acesso às instituições interessadas em atingir a sociedade com atitudes sustentáveis. A elaboração de um núcleo específico nas instalações do hospital, abrange todas as 
propostas, como a disseminação do conhecimento entre os servidores e usuários e utilizar a tecnologia como instrumento de conscientização ambiental, pois as ações poderão ser organizadas e bem elaboradas para implementação de um sistema sustentável, podendo ter como objetivo, a diminuição dos gastos com materiais, a fiscalização das atitudes dos servidores e o acompanhamento do desenvolvimento do novo sistema de gestão.

O fato importante para a implementação na organização é a vantagem que pode trazer para a empresa, pois a melhora no ambiente de trabalho pode aumentar o desempenho dos servidores e o relacionamento com os usuários, visto que se trata de um ambiente público, o acesso a informação pode ser favorável para que a disseminação do conhecimento seja feita de uma forma correta e que a população também seja atingida pela mudança deste sistema e poder constituir a conscientização ambiental buscando eliminar o desperdício.

\section{Métodos}

Este artigo apresenta como método o estudo de caso, o método observacional, empírico e a pesquisa bibliográfica, utilizando entrevista com os stakeholders da organização. O estudo de caso como método que apresenta a melhor aderência aos objetivos e às questões norteadoras do trabalho. Tull e Hawkins (1976, p. 323) afirmam que "um estudo de caso se refere a uma análise intensiva de uma situação particular". Segundo Godoy (1995), o pesquisador conduz seu trabalho a partir de um plano estabelecido, com hipóteses específicas e variáveis definidas e com o estudo de caso o pesquisador busca segurança nos dados obtidos, porém necessita se relacionar com a situação estudada para definir de forma clara as perspectivas do estudo.

Para Quivy; Campenhoudt (1998), no método de observação é importante ressaltar que este implica um alto grau de subjetividade, uma vez que as pessoas se manifestam de acordo com suas vivências, histórico de valores e aspectos culturais. Utiliza-se este tipo de pesquisa empírica quando se quer conseguir informações e conhecimento referentes a um determinado problema do qual se busca comprová-lo, ou ainda, com a intenção de descobrir novos fenômenos, percepções ou as relações entre eles. O termo pesquisa empírica, concisamente, se define como: (1) o modo de fazer pesquisa por meio de um objeto localizado dentro de um recorte do espaço social. A pesquisa empírica está centrada na escolha de aspectos das relações entre sujeitos. (2) A pesquisa empírica lida com processos de interação e face-a-face, isto é, o pesquisador não pode elaborar a pesquisa em "laboratório" ou em uma biblioteca, isolada e apenas com livros a sua volta. Nesta modalidade da elaboração do conhecimento, o pesquisador precisa "ir ao campo".

De acordo com Barros e Lehfeld (2007), a pesquisa científica por coleta de dados traz a realidade e os dados para a aplicação de técnicas em pesquisas, os autores mostram tipos que podem ser utilizados para a elaboração da pesquisa, como o diário de campo onde o pesquisador registra todos os fatos coletados, o questionário um instrumento muito utilizado para levantamento de informações, a entrevista onde o pesquisador pode analisar a postura do entrevistado obtendo dados mais relevantes e profundos, após é utilizado à interpretação dos dados onde o pesquisador registra os dados obtidos passando pelo processo de classificação, codificação e tabulação, transformando em elementos para comprovação ou não das hipóteses.

Revisão Bibliográfica. Foi realizada revisão de literatura de temas relativos à conscientização ambiental e o desperdício no setor da Saúde Pública, 
a fim de obter um conhecimento mais aprofundado do assunto. A pesquisa bibliográfica foi desenvolvida com base em material já elaborado (Gil, 2002); neste sentido, pesquisaram-se em livros, periódicos, artigos entre outros materiais. Esta etapa foi crucial, pois permitiu aos pesquisadores compreender a gestão ambiental, bem como identificar as melhorias o desenvolvimento de práticas adequadas no contexto da Saúde pública.

O conhecimento empírico é conceituado por Fachin (2003) como a resposta para ocorrências baseadas na vivência, experiência de erros e acertos, que não possuem fundamentação metodológica. Já para Ramos; Ramos; Busnello (2005) acrescenta o conceito anterior à concepção do autor em que o conhecimento empírico é estabelecido pela experiência do outro da interação humana e social, na qual são explicitados conhecimentos implícitos individuais. Dentre as metodologias ao nosso alcance, os pesquisadores as agrupam em dois níveis: 1. Metodologias Qualitativas e Observaçãoparticipante. 2. Entrevistas não-estruturadas e/ou depoimentos. A pesquisa empírica implica em refletir acerca da relação que se estabelece entre o sujeito e o objeto da pesquisa.

\section{Análise da Unidade}

O hospital iniciou suas atividades em 1931 como Sanatório, para internação compulsória de pacientes com Hanseníase conhecido na época como Lepra, em 1934 ocorreu as primeira obras para a ampliação da infraestrutura, com os avanços de tratamento para a doença em 1960 o espaço foi desocupado e o fim das internações compulsórias, após a Secretária da Saúde decidiu unir dois Hospitais para atender de forma mais ampla a sociedade e hoje é de suma importância nas especialidades que atua, sendo referência em diversas áreas de atendimento ambulatorial para população, atendendo em média 17 mil pacientes e com total de 1.500 funcionários.

Com as observações feitas, localizamos os pontos mais afetados pela falta de conscientização de servidores e usuários, que trazer prejuízo para o meio ambiente: o gasto com papel, o descarte incorreto dos materiais utilizados, a falta de compartilhamento, a falta de reuso de itens que poderiam ser reaproveitados e a falta de conhecimento, faz com que cada atitude afete o meio ambiente, pela ausência de gerenciamento especializado e ao problema cultural da organização, onde todos os materiais que são disponibilizados para a elaboração do trabalho sejam usados em excesso.

A falta de conscientização ambiental se dá pelo fato que o hospital não tem, a elaboração de projetos sustentáveis, pois para tratar das novas ações seria necessário um planejamento e investimentos, também podemos destacar o comportamento da sociedade e dos servidores, por falta de conhecimento de como deveria ser feito o descarte correto e como diminuir os recursos que são utilizados no dia a dia. Com isso a organização pode aproveitar para realinhar os padrões e criar valor ao hospital, aderindo novos conceitos e transmitindo para a população quais as ações sustentáveis que devem ser tomadas, assim desenvolvendo novas atitudes, como por exemplo: evitar o desperdício, manter a fiscalização e ampliar a conscientização.

Com base nas observações e estudo elaborado no ambiente de trabalho, podemos observar os pontos críticos do problema, que foram o descarte incorreto, onde o lixo reciclável como papel, plásticos e metais são descartados juntos com o lixo comum, prejudicando a coleta seletiva nos departamentos do hospital. Nas instalações podemos observar alguns pontos de coleta seletiva, porém, não são todos os itens que são descartados corretamente. 
Outro ponto observado é a carência de conhecimento dos servidores e usuários, que em nenhum momento são questionados ou induzidos a fazer a separação dos itens para coleta, isso mostra o desconhecimento dos pontos de coleta e a falta de organização. Com base nas informações constatamos que a ausência de um sistema de reciclagem ocasiona o aumento do desperdício de materiais e dos gastos.

\section{Coleta e Análise de Dados}

A análise das entrevistas foi feita de maneira empírica e interpretativa, por meio da utilização da análise de conteúdo. Segundo (GUBRIUM; HOLSTEIN, 2000) esse tipo de pesquisa busca apontar os "comos", e os "por quês" embasados nos discursos oriundos da análise das entrevistas levando-se em consideração as significações, procurando identificar as percepções dos stakeholders sobre o objeto de pesquisa. Um dos propósitos da utilização das entrevistas como método de coleta de dados na pesquisa qualitativa é explorar percepções, experiências, crenças e/ou motivações dos stakeholders sobre questões específicas no campo organizacional. É importante sublinhar que cada participante foi esclarecido sobre nossa intenção de pesquisa e decidiu participar voluntariamente da entrevista.

A análise foi feita em duas etapas: a) análise e compreensão das pesquisas bibliográficas e/ou documentais feitas sobre o objeto de pesquisa; b) análise e compreensão das entrevistas realizadas. Sabe-se que, desse modo, a metodologia qualitativa na pesquisa empírica, ao estabelecer relações face-aface entre o "sujeito que pesquisa" com o "sujeito que é pesquisado", permite vínculos de reflexão entre as partes envolvidas porque estão todos em presença, isto é, frente-a-frente e em diálogo.

As entrevistas foram transcritas e, em seguida, analisadas seguindo uma abordagem interpretativa, constituída por uma análise conjunta de todas as entrevistas, visando compreender as percepções gerais dos stakeholders. Foram feitas várias leituras para a seleção das unidades de significados (US) que respondem aos objetivos da pesquisa. Essas unidades foram posteriormente transcritas para uma linguagem mais apropriada para a pesquisa e agrupadas em categorias, as quais foram constituídas por convergências e divergências semânticas entre as categorias emergentes, formando assim novas interpretações (BRANDÃO, 2007). As categorias representam o resultado de um processo de redução de dados, ou seja, de um esforço de síntese para a comunicação dos aspectos mais importantes dos achados (MORAES, 1999).

As entrevistas para esse trabalho foram realizadas individualmente no local de trabalho, com stakeholders de diferentes níveis hierárquicos entre os dias 20/08 e 30/11 do ano de 2016. Para se atingir os propósitos deste estudo buscou-se formular um roteiro de entrevistas. Os dados foram levantados e desenvolvidos a partir de material já elaborado, constituído principalmente de livro e artigos científicos, para dar o devido suporte teóricoacadêmico ao estudo (DIEHL e TATIM, 2004). Efetuou-se a pesquisa de campo e entrevistas em profundidade, com questões semiestruturadas com 25 entrevistados do hospital, atuantes na cidade de Guarulhos.

Segundo Rynes; Gephart(2004), um valor importante da pesquisa qualitativa é a descrição e compreensão das reais interações humanas, percepções, sentidos, e processos que constituem os cenários da vida organizacional. Os dados são coletados por meio de entrevistas, observações e/ou análise de documentos. O que é perguntado, o que é observado e quais documentos são relevantes, dependerá da revisão da literatura. 
A coleta de dados se deu por meio de entrevista semiestruturada. Neste tipo de trabalho, o pesquisador deve seguir um conjunto de questões previamente definidas, mas ele o faz em um contexto muito semelhante ao de uma conversa informal, tendo abertura para incluir novas questões, se necessário, e análise de documentos, por meio das questões elaboradas buscou-se compreender se os stakeholders têm conhecimento sobre a importância que a conscientização ambiental pode trazer ao nosso ambiente de trabalho e ao nosso dia a dia, melhorando significativamente as ações e atitudes com relação ao meio ambiente.

\section{RESULTADOS E DISCUSSÕES}

Os resultados descritos a seguir foram baseados nas informações colhidas nas entrevistas, também foram colhidas informações nos sites da organização. Estas contribuíram para complementar o estudo. Os resultados visaram a responder, as percepções diante dos impactos causados pela falta de conscientização ambiental dos servidores, diante do excesso de desperdício de materiais, utilizados na elaboração dos trabalhos desenvolvidos no dia a dia do servidor, e o descaso da importância e benefícios que a reciclagem pode causar no meio ambiente. As discussões apresentadas buscam traduzir a interpretação do pesquisador, construída a partir da análise das respostas obtidas, bem como, os dados obtidos a partir da observação in loco. As informações foram trabalhadas de forma a apresentar as percepções dos stakeholders, com a finalidade de elaborar ações que venham a contribuir para ampliar o conhecimento sobre os benefícios, e melhorar o desempenho e a produtividade dos servidores por meio de novas atitudes, utilizando a conscientização ambiental para eliminar o desperdício de materiais e gerir a reciclagem e o descarte correto.

Os estudos e análises feitas demonstraram que o problema é comportamental e processual, pois, necessita de ser regulamentado e implantado para a obtenção de um resultado positivo. Para se obter o sucesso, é necessário um processo contínuo, incluindo toda a população, para que possa ser elaborado um sistema de gestão sustentável nas instalações do governo e também nas residências. $\mathrm{O}$ governo deve trazer para si a responsabilidade de conscientizar a sociedade sobre a sustentabilidade, fazendo com que diminuíssem os gastos públicos e aumenta-se a conscientização. As ONGs trabalham para atingir um bairro em específico, trazendo a mudança para seu determinado público, sendo um importante aliado do governo na disseminação do conhecimento necessário, sendo assim as instalações públicas devem seguir um modelo sustentável para garantir o sucesso. 
Quadro 1. Percepções acerca da Gestão Ambiental na saúde pública e como a conscientização ambiental pode contribuir para eliminar o desperdício e ampliar as ações a favor do meio ambiente.

\begin{tabular}{|c|c|c|}
\hline & Levante as dificuldades de implementação & Propostas \\
\hline $\begin{array}{l}\text { Diretores } \\
\text { (5) }\end{array}$ & $\begin{array}{l}\text { As percepções encontradas neste público foram em } \\
\text { média satisfatória, pois nem todas as pessoas entrevistadas têm } \\
\text { um conhecimento sobre o assunto, mostrando que cada pessoa } \\
\text { age da maneira que acha ser o correto. Os stakeholders } \\
\text { mostraram como podemos melhorar e evoluir o conhecimento e } \\
\text { a educação ambiental no ambiente organizacional, incluindo no } \\
\text { dia a dia de cada servidor uma gestão eficiente, buscando ampliar } \\
\text { o conhecimento das pessoas e a corresponsabilidade entre a } \\
\text { sociedade e a organização, sendo necessária a implantação de um } \\
\text { núcleo específico para elaboração de um planejamento legal de } \\
\text { acordo com as normas estabelecidas pelo governo encontrado na } \\
\text { ISO } 14001 \text {, para satisfazer os servidores e os usuários. }\end{array}$ & $\begin{array}{l}\text { Montar um } \\
\text { núcleo } \\
\text { específico para } \\
\text { elaboração do } \\
\text { planejamento }\end{array}$ \\
\hline $\begin{array}{l}\text { Operacional } \\
\text { (13) }\end{array}$ & $\begin{array}{l}\text { O estudo está focado na melhoria do ambiente } \\
\text { organizacional e o aumento do conhecimento dos stakeholders } \\
\text { sobre a importância do meio ambiente. O foco do estudo mostra } \\
\text { que o desconhecimento da atual situação e maneira correta do } \\
\text { comportamento ó o principal inimigo para a elaboração de ações } \\
\text { que possam corresponder sustentavelmente para o meio } \\
\text { ambiente. O público avaliado alegou falta de incentivo e } \\
\text { ambiente propício para o planejamento, o desperdício de } \\
\text { recursos e descarte incorreto faz parte da cultura da empresa, já } \\
\text { que não tem uma gestão sustentável que possam levar em } \\
\text { consideração cada item descartado incorretamente e itens que } \\
\text { poderiam ser reaproveitados ou doados a outras organizações. O } \\
\text { público apresenta a hipótese de incluir no dia a dia dos servidores } \\
\text { campanhas, palestras para agregar conhecimento para que os } \\
\text { mesmos possam atribuir ao ambiente organizacional, juntamente } \\
\text { com um sistema de descarte correto e a diminuição dos recursos } \\
\text { utilizados. }\end{array}$ & $\begin{array}{l}\text { Disseminação } \\
\text { do } \\
\text { conhecimento } \\
\text { com } \\
\text { campanhas e } \\
\text { palestras }\end{array}$ \\
\hline Usuários (7) & $\begin{array}{l}\text { O público pesquisado mostra desconhecimento sobre o } \\
\text { assunto, porém disponibiliza ideias para que a organização possa } \\
\text { implantar em suas instalações, para agregar conhecimento ao } \\
\text { público em geral, pois se tratando de um hospital cerca de } 17 \text { mil } \\
\text { pessoas seriam atingidas pelo conhecimento. O público mostra } \\
\text { interesse em adquirir novas técnicas que poderiam ser utilizadas } \\
\text { em sua residência, para isso propõem a utilização da tecnologia } \\
\text { para auxiliar na conscientização ambiental da sociedade } \\
\text { mostrando quais as atitudes que deveriam ser tomadas para } \\
\text { aumentar as ações sustentáveis, qual o descarte correto e como } \\
\text { diminuir o desperdício. Outro ponto importante é a implantação } \\
\text { de estudos nas escolas de ensino fundamental e médio e assim } \\
\text { fazer com que as crianças e adolescentes possam contribuir e } \\
\text { gerir novos métodos para o futuro. }\end{array}$ & $\begin{array}{l}\text { A tecnologia } \\
\text { como } \\
\text { instrumento de } \\
\text { conscientização } \\
\text { ambiental }\end{array}$ \\
\hline
\end{tabular}

Fonte: Dados da pesquisa 
As convergências percebidas foram: o desconhecimento do assunto e qual seriam as melhores atitudes que poderiam ser tomadas, para deixar de afetar o meio ambiente e passar a ter atitudes mais responsáveis e sustentáveis. Além da falta de incentivo e da implementação de um sistema de gestão sustentável, para que possa ser trabalhada a disseminação do conhecimento, para intensificar o conhecimento as pessoas, mostrando a importância do meio ambiente.

Por outro lado, destacou-se as divergências, entre as pessoas entrevistadas, onde apresentaram observações que o principal erro vem do governo, que não disponibiliza meios para que o descarte seja feito corretamente e outras mostraram que a população deveria tomar atitudes mais sustentáveis, mantendo um conjunto entre a sociedade e governo, para diminuir os problemas e aumentar a conscientização ambiental, buscando o compartilhamento das informações entre o governo e a sociedade.

Segundo Souza, et al (2014), no Brasil foi realizado diversas pesquisas sobre a aprendizagem contínua e suas consequências, onde o foco é o desenvolvimento da comunicação nas organizações, mostrando a expansão desta prática; as organizações devem estabelecer métodos para facilitarem a aprendizagem através da comunicação, podemos considerar alguns métodos como as palestras e campanhas, para disseminar a conscientização ambiental no ambiente de trabalho.

Segundo Layrargues (2000) a empresa que utiliza em suas instalações instrumentos de tecnologia limpa, se beneficia com privilégio empresarial, onde são localizados instrumentos de controle para direcionar a sustentabilidade, como a implementação do Sistema de Gerenciamento Ambiental, que a organização pode utilizar para formar a qualidade ambiental coletiva e mudar significativamente a relação entre o meio ambiente e a organização, através de planejamento e controle, buscando ampliar o conhecimento dos stakeholders

De acordo com programa A3P do ministério do meio ambiente a organização pode formalizar um núcleo específico para a fiscalização, elaboração e planejamento do sistema de gestão sustentável, para que a empresa tenha sucesso na aplicação deste sistema, deve-se ter: comprometimento e o envolvimento de todos os funcionários, que podemos considerar como ponto principal para a disseminação do conhecimento, esses podem formar de opiniões e trazer a mudança, para aqueles que estão envolvidos com a entidade como usuários e fornecedores.

O desperdício nas instalações públicas está relacionado com a falta de conscientização dos servidores e usuários, através das observações e estudos analisamos que, a cultura organizacional está baseada em formas de desregramento por não terem o devido conhecimento e o incentivo necessário para a regularização de um sistema satisfatório ao meio ambiente. Segundo Barbieri (2004) os problemas ambientais exigem novas atitudes de empresas que acreditam que o meio ambiente pode ampliar seu crescimento, sendo assim podemos identificar que as organizações devem agregar ao seu portfólio a conscientização ambiental, e assim diminuindo os desperdícios dentro da organização.

A solução para a questão problema pode ser definida em forma de corresponsabilidade entre a organização e a sociedade, além da implementação de um núcleo responsável para o planejamento de ações que possam definir a diminuição do desperdício e as estratégias propostas para obter a mudança na organização. O núcleo deverá utilizar em seu planejamento as orientações da $\mathrm{A} 3 \mathrm{P}$, juntamente com a ISO 14001 onde podem ser encontradas as diretrizes que devem ser seguidas, garantindo que a empresa tenha todas as instruções necessárias para implantar o programa e alcançar os padrões necessários para 
disseminar o conhecimento sobre a importância do meio ambiente e a responsabilidade de cada um na sociedade, para atingir o objetivo da organização.

Para que uma empresa tenha sucesso na implementação de um novo Núcleo de Gestão Sustentável, a organização deve apresentar a seus colaboradores a realidade da empresa e as ações que serão utilizadas, desta forma a empresa conseguirá alcançar a mudança de uma forma evidente; para isso, é necessário um planejamento focado na distribuição destas informações. Segundo Gomes (2000) quando uma solução é aceita de verdade há pouca variação na unidade de trabalho, isso quer dizer que, todos os membros aceitaram a mudança, fazendo com que a empresa não tenha problema para dar andamento na alteração de comportamento e das práticas, com isso a organização pode conseguir manter a sustentabilidade, com foco na redução do desperdício.

De acordo com os dados constantes no quadro 1, observou-se que as percepções dos stakeholders que responderam o questionário demonstrando desconhecimento e falta de incentivo.

As convergências observadas foram o desconhecimento e a falta de incentivo aos servidores e usuários para manter atitudes sustentáveis, pois os stakeholders detêm de pouco conhecimento e incentivo, já que a coleta seletiva não está regulamentada e regularizada em todos os bairros e somente alguns departamentos do hospital detêm do acesso específico para a reciclagem. Os servidores formam um grupo de opiniões e com conhecimento adequado e atitudes responsáveis, podem trazer a mudança para os usuários, diante da visita aos departamentos, apresentando as atitudes sustentáveis que pode ser utilizada por cada indivíduo, assim os usuários serão atingidos pelas mudanças.

Por outro lado, da mesma maneira destacamos as divergências, onde temos a divisão de opiniões dos stakeholders: alguns demonstram que as atitudes podem ser alteradas pelo próprio indivíduo, e outros, que o governo deve incentivar as unidades a transmitir informações importantes, como, quais as formas de ajudar o meio ambiente e disponibilizar meios para que a conscientização ambiental seja divulgada e transmitida a todos aqueles que necessitam de reforço para a mudança. Para que o sistema de gestão sustentável tenha sucesso é necessário que todos estejam envolvidos no decorrer das etapas do processo.

Segundo Cortez; Ortigoza (2007) o programa $3 \mathrm{M}$ demonstra que a sociedade tende a eliminar ou substituir um produto ou reduzir o uso excessivo, sendo assim, a organização deve buscar eliminar o uso excessivo de materiais, utilizados para a elaboração de trabalhos, buscando utilizar mais a tecnologia no ambiente de trabalho, não sendo necessário o excesso de impressões na repartição, trabalhar com a inovação, buscando meios de atingir o objetivo, agindo de forma mais sustentável, gerando menos desperdício nos departamentos.

A elevação da responsabilidade dos colaboradores, a separação dos itens para coleta correta e o aumento do incentivo, quanto ao, controle dos gastos com materiais e recursos é extremamente importante. Para conseguir com que as metas estabelecidas sejam atingidas, a organização deve utilizar a prática dos 3Rs (Reduzir, Reutilizar e Reciclar) visando minimizar o desperdício de materiais; para Ashley (2002) as empresas devem ter compromisso com a sociedade, expressando por meios de atos e atitudes que podem afetar positivamente a comunidade.

De acordo com Gonçalves, Mourão (2011) há um forte impacto na elaboração dos trabalhos após treinamentos, pois aumentam as oportunidades e expectativas positivas na execução das tarefas; a empresa deve, buscar diminuir o retrabalho, elaborando as tarefas com mais atenção, para que não 
seja necessária nova impressão. Os usuários e servidores devem ser incentivados e conscientizados a diminuir os gastos com recursos indevidos, elaborando seus trabalhos com mais atenção e responsabilidade, para que a empresa consiga reduzir os custos.

Segundo Quintas (2006) o poder público é mediador do processo de gestão ambiental, pois é detentor de poder e obrigação para que as organizações sigam a legislação, para controle dos recursos ambientais utilizados, por este motivo, a organização deve criar um Núcleo especializado para planejamento e controle das ações de reciclagem, com uma equipe comprometida, para a implantação da gestão sustentável, buscando incentivar os servidores com campanhas e novos projetos para elaboração de ações, que possam ser apresentadas e disseminadas na organização. Para atingir a população com a mudança da empresa, esta pode criar formas de adquirir certificações e selos verdes para agregar valor sustentável e aumentar a credibilidade da organização.

A despeito das limitações da pesquisa, a primeira delas está relacionada à amostra analisada e seu caráter não probabilístico que impedem que os resultados gerados por essa pesquisa sejam generalizados para todo o segmento ou para todas as empresas e, a segunda, por se tratar de um caso único, não possibilita a comparação com outras empresas, a fim de identificar as convergências e divergências existentes.

\section{CONCLUSÃO}

O estudo atingiu seus objetivos respondendo à questão problema, além de contribuir com a literatura referente à Conscientização ambiental. O objetivo deste trabalho foi, contribuir com a sustentabilidade através da disseminação do conhecimento referente ao meio ambiente com atitudes simples, despertar o conhecimento dos servidores e da sociedade e, por conseguinte eliminar o desperdício nas instalações públicas, assim melhorando o ambiente de trabalho; de acordo com Sousa (2008) podemos utilizar da adoção de uma política de corresponsabilidade e de diálogo com a sociedade trazendo para a realidade uma gestão otimizada de seus recursos naturais. Para tal foi realizado um estudo de caso, com abordagem qualitativa por meio de entrevistas, nos setores administrativos e nas recepções do hospital. A revisão de literatura sugere que existe uma relação entre Donaire (1994) e MMA - Ministério do Meio Ambiente (2016).

O estudo alcançou seus objetivos de trazer para a realidade as ações que deveriam ser adotadas pela empresa para obter sucesso na implementação de uma gestão sustentável, para diminuir o desperdício e ampliar a conscientização dos servidores melhorando o ambiente de trabalho; os principais resultados demonstraram que o governo deve estabelecer normas para que as suas entidades e instalações possam regularizar e implementar uma gestão sustentável, a fim de otimizar os recursos utilizados e ampliar a conscientização da sociedade, através dos servidores, que têm acesso diário à população, por este motivo deve haver uma conscientização interna dos colaboradores para atingir os usuários e ampliar as ações, modificando as atitudes e conseguir colocar em prática, a redução de resíduos e a ampliação de um sistema sustentável no país.

Diante do exposto as implicações mais relevantes são de natureza empírico/gerencial, pois durante a realização da pesquisa constatou-se a necessidade de investimento e planejamento que são eixos empíricos e gerenciais mais condizentes com as necessidades expressas da organização no atual contexto da empresa. (FLEURY; FLEURY, 2001). 
Como sugestão de estudos futuros, é necessário ampliar a amostra para outras revisões de literatura, ampliar o período de tempo para possibilitar uma visão mais abrangente do emprego dos métodos de pesquisa, podendo apresentar contribuições significativas como, por exemplo, permitir novas contribuições metodológicas na área e ampliar a análise dos resultados e, por fim, a realização de futuras pesquisas ligando o objeto de pesquisa conscientização ambiental com as escolhas metodológicas que se mostraram relevantes no sentido de verificar tendências e oportunidades de pesquisa, para que os profissionais e gestores da área tenham mais clareza sobre o tema.

Todos os autores declararam não haver qualquer potencial conflito de interesses referente a este artigo.

\section{REFERÊNCIAS}

ASHLEY, P. A. Ética e responsabilidade social nos negócios. São Paulo: Saraiva, 2002

CAMPOS, L. M. S.; LERÍPIO, A. de Á. Auditoria Ambiental: uma ferramenta de gestão. $1^{\mathrm{a}}$ Edição. São Paulo; Atlas, 2009, 152 páginas.

COLLIS, J.; HUSSEY, R. Pesquisa em administração: um guia prático para alunos de graduação e pós-graduação: um guia prático para alunos de graduação e pós-graduação 2.ed. Porto Alegre: Bookman, 2005. 349p.

BARATA, M. M. de L. et al. A gestão ambiental no setor público: uma questão de relevância social e econômica. Ciência e Saúde coletiva, 12(1):165-170, 2007

BARBIERI, J. C. Gestão Ambiental Empresarial: conceitos, modelos e instrumentos, $1^{\mathrm{a}}$ ed. São Paulo: Saraiva, 2004.

BARBIERI, J. C. Gestão Ambiental Empresarial. São Paulo: Saraiva, 2007.

BARROS, A. J. da S.; LEHFELD, N. A. de S. Fundamentos da Metodologia Científica. $3^{\text {a }}$ edição. São Paulo: Pearson Prentice Hall, 2007, 160 páginas.

BURGESS, P.W.; SIMONS, J.S. Theories of frontal lobe executive function: clinical applications. In: HALLIGAN, P.W.; WADE, D.T. Effectiveness of rehabilitation for cognitive deficits. Oxford: Oxford University, 2005.

BRANDÃO, C. R. Reflexões sobre como fazer trabalho de campo. Sociedade e Cultura. v. 10, n. 1: p. 11-27, jan. /jun. 2007.

Cortez, A. T. C; OrTigozA, S, A, G; Consumo Sustentável: Conflitos entre a necessidade e desperdício. (Org.). - São Paulo: Editora UNESP, 2007.

DALLAS, N. Como tornar sua empresa ecologicamente responsável [tradução de Bernardo Araújo]. Rio de Janeiro, Sextante, 2009. DIEHL, A. TATIM, A. et al, Pesquisa em Ciências Sociais Aplicadas; Métodos e Técnicas, São Paulo: Pearson Prentice Hall, 2004.

DONAIRE, D. Considerações sobre a influência da variável ambiental na empresa. $R A E$. São Paulo, v. 34, n.2, p. 68-78, março-abril, 1994.

FACHIN, O. Fundamentos de metodologia. 4. ed. São Paulo: Saraiva, 2003.

FANTIN, M. E. Educação ambiental, saúde e qualidade de vida. In: LIMA, W. Aprendizagem e classificação social: Um desafio aos conceitos. [Livro eletrônico], 2004 /Maria ENEIDA F. E. O. Curitiba: InterSaberes, 2014 - (Série Educação Ambiental). $2 \mathrm{Mb} ; \mathrm{PDF}$

FLEURY CAIXETA-FILHO, J. V. e MARTINS, R. S. Gestão Logística do Transporte de Cargas, São Paulo: Atlas, 2001.

GIL, A.C. Como Elaborar Projetos de Pesquisa. $4^{\mathrm{a}}$ ed. Atlas. São Paulo, Brasil. 2002.

GODOY, A. S. Introdução à pesquisa qualitativa e suas possibilidades. Revista de Administração de Empresas da EAESP/FGV, São Paulo, v. 35, n. 2, p. 57-63, mar./abr. 1995.

GONÇALVES, A; MOURÃO, L, A expectativa em relação ao treinamento influencia o impacto das ações de capacitação? Revista de Administração Pública - RAP — Rio de Janeiro 45(2):483-513, mar./abr. 2011

GOMES, E. B. P. Cultura Organizacional Um Estudo De Caso, Disponível em: http://nti.facape.br/ruth/adm-

comport_organ/Cultura_organizacional.pdf, acesso: 06 dez 2016.

GUBRIUM, J. F.; HOLSTEIN. Analyzing Interpretative Practice. In: DENZIN, N. K.; 2000

HERRERA, A. O. A Grande Jornada. Ed. Paz e Terra, São Paulo, 1982.

ISO 14001 - Sistema de Gestão Ambiental ABNT NBR ISO 14001. Disponível em: 
http://www.labogef.iesa.ufg.br/labogef/arquivos/dow nloads/nbr-iso-14001-2004_70357.pdf. Acesso em 8 out 2016.

LAYRARGUES, P. P. Sistemas de Gerenciamento Ambiental, Tecnologia Limpa e Consumidor Verde: A Delicada Relação Empresa-Meio Ambiente no Eco capitalismo. RAE - Revista de Administração de Empresas, São Paulo, v. 40, n. 2, p. 80-88, (Abr./Jun. 2000).

MARTINS, M.C.F. Clima Organizacional. In: SIQUEIRA, M.M. M (Org.) Medidas do Comportamento Organizacional: Ferramentas de diagnóstico e gestão. Porto Alegre: Artmed, 2008.

MMA - Ministério do Meio Ambiente: A3P Agenda Ambiental na Administração Pública. Disponível

em

http://www.mma.gov.br/destaques/item/8852. Acesso em 8 out 2016.

MORAES, R. Análise de conteúdo. Revista Educação, Porto Alegre, v. 22, n. 37,p. 7-32, 1999.

Projeto de Desenvolvimento de ações de preservação ambiental na UFCSPA. Disponível em:

http://www.ufcspa.edu.br/ufcspa/institucional/politica s_gestaoambiental.pdf. Acesso em 08 out 2016.

Projetos de Consciência Ambiental. Disponível em: http://www.codeca.com.br/projetos_de_consciencia_a mbiental.php. Acesso em 08 out 2016.

QUINTAS, J. S: Introdução à gestão ambiental pública. $2^{\mathrm{a}}$ ed. revista. - Brasília: Ibama, 2006. 134p.; $21 \mathrm{~cm}$. (Coleção Meio Ambiente. Série Educação ambiental, 5)

QUIVY, R.; CAMPENHOUDT, L. Manual de investigação em Ciências Sociais. Lisboa: Gradiva, 1998.

RAMOS, P.; RAMOS, M. M.; BUSNELLO, S. J. Manual prático de metodologia da pesquisa: artigo, resenha, projeto, TCC, monografia, dissertação e tese. 2005.

ROSENBERG, N. Perspectives on Technology. Cambridge University Press, Cambridge, 1976.

RYNES, S., GEPHART, R. P., JR. From the editors: qualitative research and the Academy of Management Journal. Academyof Management Journal, 47 (4), 454-461. 2004.

SILVA, R. C.; BARKI, T. V. P. Compras públicas compartilhadas: a prática das licitações sustentáveis. Revista do Serviço Público Brasília 63 (2): 157-175 abr/jun 2012

SOARES, P.S.M, et al. CARVÃO BRASILEIRO: TECNOLOGIA E MEIO AMBIENTE, Centro de Tecnologia Mineral Ministério da Ciência e
Tecnologia Coordenação de Processos Metalúrgicos e Ambientais Serviço de Tecnologias Limpas; 2008, disponível em livroaberto.ibict.br. Acesso em 08 out 2016.

SOUSA, A.C.A; A evolução da política ambiental no Brasil do século $\mathrm{XX}$, disponível em [PDF] - 2008, acessado em 24.nov.2016.

SOUZA, F. H. et al. Interseção entre a gestão do conhecimento e a cultura organizacional: um estudo sobre a percepção dos gerentes de projetos. Revista de Gestão e Projetos, v. 5, n. 2, p. 51-67, 2014

TULL, D. S.; HAWKINS, D. I. - Marketing Research, Meaning, Measurement and Method. MacmillanPublishingCo, Inc., London, 1976.

YOUNG, C. E. F; LUSTOSA, M. C. J. - Meio Ambiente e Competitividade na Indústria Brasileira; Revista de Economia Contemporânea, ie.ufrj.br; 2001. 